\title{
Impact of kinesiophobia on physical function and quality of life in functional ankle instability individuals: an observational study
}

\author{
Prachita P. Walankar ${ }^{1 *}$, Vrushali P. Panhale ${ }^{1}$ and Kanchi M. Vyas ${ }^{2}$
}

\begin{abstract}
Background: Functional ankle instability is a common musculoskeletal condition affecting the community. It is characterized by repetitive bouts of giving away, recurrent sprains, and sensation of instability leading to functional deficits in an individual. The present study aimed to assess the influence of kinesiophobia on physical function and quality of life in participants with functional ankle instability. A cross-sectional study was conducted in 30 participants with functional ankle instability. Kinesiophobia was assessed using the 17-item Tampa Scale of Kinesiophobia, physical function using the Foot and Ankle Ability Measure (FAAM) and the FAAM-Sport version (FAAM-S), and quality of life using SF-36.
\end{abstract}

Results: The TSK score showed a moderate negative correlation with FAAM-S ( $r=-0.5, p=0.005)$ and a weak negative correlation with SF-36 physical component summary $(r=-0.42, p=0.02)$. However, TSK showed no significant correlation with FAAM-ADL and SF-36 mental component summary.

Conclusion: Increased fear of movement, reduced physical function, and health-related quality of life were observed in functional ankle instability individuals. Hence, evaluation of these parameters is imperative in these individuals.

Keywords: Functional ankle instability, Fear, Function, Movement, Quality of life

\section{Background}

Lateral ankle sprain is one of the common musculoskeletal injuries reported among physically active individuals $[1,2]$. Although there is a high incidence of ankle sprains, it is considered a harmless injury as a smaller number of patients seek treatment and adhere to preventive strategies [3]. It has been reported that individuals who suffer from an ankle sprain are prone to recurrence which can lead to long-term health issues [4]. It has been observed that ankle sprains account for 10 to $44 \%$ of injuries in physically active populations $[2,5]$.

\footnotetext{
* Correspondence: prachita30@gmail.com

'Department of Musculoskeletal Sciences, MGM College of Physiotherapy, Navi Mumbai, India

Full list of author information is available at the end of the article
}

Also, 32 to $74 \%$ of patients with a previous ankle sprain report some type of chronic symptom, and 32 to $47 \%$ report functional ankle instability $[6,7]$.

Chronic ankle instability is a condition characterized by repetitive bouts of lateral ankle instability with residual symptoms like pain, swelling, loss of function, joint instability, and a feeling of giving way $[8,9]$. Chronic ankle instability is a wide continuum encompassing both mechanical and functional ankle instability $[9,10]$. Mechanical instability results from increased joint laxity and is usually related to damage of the ligamentous structure of the ankle [11]. Functional ankle instability has been reported commonly among 32 to $47 \%$ patients with symptoms including sensations of giving way, subsequent sprains, and instability [6]. Altered 
proprioception, slower reflex reactions, arthrogenic muscle inhibition, impaired postural control, muscle weakness, and subtalar instability are the possible causative factors leading to functional ankle instability $[12,13]$.

The most important criterion recognized in the health care to define the chronicity of the problem is the patient's perspective about it [14]. Assessment of quality of life in health-related condition has been documented as a key aspect in the era of evidence-based practice as it renders important information about patient's perception of their health condition [15]. Quality of life is a multidimensional phenomenon comprising of several domains like physical, psychological, and social which are influenced by individual experiences, expectations, beliefs, and perceptions [16]. It is the patient awareness of their current level of functioning and satisfaction when compared to what is perceived to be ideal by them that varies from individual to individual [17]. Quality of life is usually quantified using patient-reported outcome measures as it assimilates patient's outlook and assists the therapist to plan the management as per the evidence-based practice paradigm [18]. These measures can be either global (generic) or region specific. Generic outcome measures target evaluation of several health domains imparting a broader knowledge of individual's health status [16].

Psychological factors have an influence on the development of chronic health conditions affecting the level of function and quality of life of an individual [19]. Kinesiophobia or "fear of movement" is defined as an excessive, irrational, and debilitating fear of physical movement and activity as a result of a feeling of susceptibility to painful injury or re-injury [20]. There is development of reciprocal process involving movement-related fear, kinesiophobia, and avoidant behavior leading to a vicious cycle of a negative experience [19]. This further causes avoidance of functional activities and disability affecting the physical and mental health-related quality of life which acts like a barrier and decreases adherence to management [19]. Fear has an impact on the patient perception of disability which should be targeted during the rehabilitation to achieve successful outcome [21]. A recent study showed that there is no difference in Tampa Scale of Kinesiophobia scores between chronic ankle instability patients and copers. Also, no relation was established with selfassessed disability in those with chronic ankle instability [22]. This requires further investigation about kinesiophobia, physical function, and quality of life in these patients. Hence, the primary purpose of this study was to evaluate the association between kinesiophobia, disability, and quality of life in functional ankle instability individuals.

\section{Methods}

A cross-sectional study was conducted at a tertiary health care center from August to December 2019 after receiving approval from Institutional Research Review Committee. Sample size was determined using G*Power 3.1.9.4 software with $\alpha$ (two-tailed) $=0.05, \beta=0.2$, and $r$ $=0.5$. The sample size was 29 which was then rounded off to 30 subjects.

A total of thirty individuals (age $=23.27 \pm 3.07$ years, body mass index $\left.=24.15 \pm 3.69 \mathrm{~kg} / \mathrm{m}^{2}\right)$ with unilateral functional ankle instability (7 men [ 23.33\%], 23 women [76.67\%]) were recruited from the local university and community.

The inclusion criteria were history of at least 1 or more ankle sprains in the past 6 months, repeated episodes of "giving-way" and/or recurrent sprain and sensation of ankle instability or giving way, and perceived instability determined by a score $\geq$ " 11 " on the Identification of Functional Ankle Instability (IdFAI) [23]. Exclusion criteria were previous history of fracture or surgery in the lower extremity, history of any neurological or cardio-respiratory diseases, and previous history of any self-reported musculoskeletal or neurovascular injuries and disorders in the lower extremity within the previous 6 months other than lateral ankle sprain. The functional ankle instability participants were assessed on the basis of inclusion and exclusion criteria by physiotherapy personnel with postgraduate qualification.

A brief explanation about the objective of the study was given to the subjects. Participation in the study was on a voluntary basis, and a written informed consent was obtained from the subjects before participating in the study. The data was collected in a single session.

Basic demographic characteristics like age, gender, and body mass index were noted. The Foot and Ankle Ability Measure (FAAM), Tampa Scale of Kinesiophobia (TSK), and 36-Item Short Form Health Survey questionnaire (SF-36) were used to assess physical function, kinesiophobia, and quality of life respectively in functional ankle instability individuals. The primary investigator scored all of the instruments for analysis based on the established guidelines.

\section{Outcome measures}

Tampa Scale for Kinesiophobia (TSK), a 17-item measure, was used to assess the fear of re-injury. Each item was rated on a 4-point Likert scale ranging from strongly disagree to strongly agree. A total score is calculated after inversion of the individual scores of items 4, 8, 12, and 16. The total score ranges from a yielding score of 17 to 68 . The higher the score, the higher is the level of kinesiophobia [20, 24]. The TSK has shown acceptable 
internal consistency (Cronbach alpha from 0.68 to 0.80 ) and test-retest reliability $(r=0.78)$ [25].

Foot and Ankle Ability Measure (FAAM), a regionspecific instrument, computes functional deficits associated with foot and ankle conditions [26]. It contains two individually scored subscales-21-item FAAM-Activities of Daily Living (FAAM-ADL) and 8-item sports (FAAM-Sport) subscales. Each item was scored on a 5point Likert scale ranging from no difficulty at all to unable to do. The total score yielded a range from 0 to 84 (FAAM-ADL) and 0 to 40 (FAAM-Sport) [26]. The content validity, construct validity, test-retest reliability, and responsiveness of FAAM have been well established in musculoskeletal foot and ankle disorders [26, 27]. The higher the score, the better is the function.

The Quality of Life was assessed using the 36-Item Short Form Health Survey questionnaire (SF-36) [28]. The validity and reliability are well established in the literature [29]. It comprises eight subscales which are grouped as physical component summary (PCS) and mental component summary (MCS). PCS includes physical functioning, role limitations due to physical health, bodily pain, and general health whereas MCS includes role limitations due to emotional problems, social functioning, vitality, and mental health.

\section{Statistical analysis}

Data were analyzed using the Statistical Package for the Social Sciences software version 20.0 (IBM Corporation, Armonk, NY, USA). Descriptive statistics were used to describe the demographic characteristics of the students. Mean and standard deviation values were calculated for continuous variables. Categorical variables were reported as proportions and percentages. The normality of the data was assessed using the Shapiro-Wilk test. The data was normally distributed. Pearson correlation test was used to assess the association between the variables. The correlation coefficient interpretation was as follows: 0 to 0.3 is weak, 0.4 to 0.6 is moderate, and 0.7 to 1.0 is a strong correlation. A $5 \%$ level of probability was considered statistically significant.

\section{Results}

Demographic characteristics of the participants are displayed in Table 1. The mean age of participants was $23.27 \pm 3.07$ years. Out of the 30 unilateral functional ankle instability participants, there were 7 men [23.33\%]

Table 1 Demographic characteristics of the participants

\begin{tabular}{ll}
\hline Variable & Mean \pm SD \\
\hline Age (in years) & $23.27 \pm 3.07$ \\
Body mass index (in $\left.\mathrm{kg} / \mathrm{m}^{2}\right)$ & $24.15 \pm 3.69$ \\
\hline
\end{tabular}

and 23 women [76.67\%]. The mean body mass index of participants was $24.15 \pm 3.69 \mathrm{~kg} / \mathrm{m}^{2}$.

The mean values of TSK, FAAM-ADL, and FAAMSport have been represented in Table 2.

Also, mean scores of SF-36, component summary wise, and eight domains are represented in Table 3.

The TSK correlations with the FAAM-ADL, FAAM-S, and SF-36 Component Summary Measures are presented in Table 4 . The TSK showed a moderate negative correlation with FAAM-S $(\mathrm{r}=-0.5, \mathrm{p}=0.005)$ and a weak negative correlation with SF-36 physical component summary $(r=-0.42, p=0.02)$. However, TSK showed no significant correlation with FAAM-ADL and SF-36 mental component summary.

\section{Discussion}

The primary purpose of our study was to determine the association between kinesiophobia, disability, and quality of life in functional ankle instability individuals. We identified a moderate negative association of TSK with FAAM-Sport and a weak negative association between TSK and SF-36 physical component summary. However, TSK showed no significant relation with FAAM-ADL and SF-36 mental component summary.

A cross-sectional study was conducted in 85 subjects with foot and ankle pathology to analyze the impact of pain-related fear of movement on foot and ankle disability. It was reported that age, chronicity of symptoms, ROM deficit, and Tampa Scale of Kinesiophobia were significant contributors to foot and ankle self-reported disability. Also, pain-related fear of movement was the strongest single contributor to disability in the ankle pathology [30]. This fear of re-injury accelerates avoidant behavior in an individual to diminish harmful effects or prevent further injury [30]. Another study analyzed fear of movement in 29 chronic ankle instability individuals and 29 copers using the Tampa Scale of Kinesiophobia. Individuals requiring immobilization and/or non-weight bearing for at least 3 days following ankle sprain and resumed physical activity without any limitation and complication for the last 12 months were classified as copers. Individuals in chronic ankle instability were those with lateral ankle sprain that required immobilization and/or non-weight bearing for at least 3 days, multiple episodes of giving way within the past year, and at least 1 recurrent sprain between 3 and 6 months prior to study participation. It reported that fear of re-injury does not differ between those with chronic ankle instability and copers, although participants with chronic ankle instability noted a lack of confidence in their affected ankle during performance of activities of daily living [22]. Also, there was no correlation observed between TSK scores and self-reported disability in those with chronic ankle instability [22]. 
Table 2 Tampa Scale of Kinesiophobia, Foot and Ankle Ability Measure-Activities of Daily Living, and Foot and Ankle Ability Measure-Sport scores

\begin{tabular}{llll}
\hline Variable & Mean \pm SD & \multicolumn{2}{l}{$\mathbf{9 5 \% \text { confidence interval }}$} \\
\cline { 3 - 4 } & & Lower bound & Upper bound \\
\hline Tampa Scale of Kinesiophobia & $36.47 \pm 6.53$ & 34.02 & 79.87 \\
Foot and Ankle Ability Measure-Activities of Daily Living & $86.79 \pm 8.68$ & 83.58 & 90.03 \\
Foot and Ankle Ability Measure-Sport & $74.24 \pm 15.53$ & 68.44 & 80.04 \\
\hline
\end{tabular}

Quality of life is a multidimensional concept and requires holistic understanding. According to the World Health Organization, "Quality of Life" represents an individual's perception of his/her position in life with respect to the culture and value systems in which he lives and in relation to his goals, expectations, standards, and concerns [31]. It is regarded as the knowledge of the current level of performance and satisfaction of an individual when compared to what is perceived to be ideal by them. This phenomenon is unique to every person [17]. Quality of life is based on various components like physical health, mental status, level of independence in performance of daily activities, social relationships, and environment. Physical and mental affection in quality of life hinders the participation of an individual in the activities of daily living. This in turn reduces the functional performance of an individual which has an impact on social participation of an individual that affects both physical and psychosocial domains.

A recently published cross-sectional study evaluated regional and global health-related quality of life in 59 middle-aged participants consisting of 18 chronic ankle instability, 17 ankle-sprain copers, and 24 healthy controls. Foot and Ankle Disability Index (FADI) Activities of Daily Living and Sport subscales and PatientReported Outcomes Measurement Information System Adult Profile were used to assess regional and global health-related quality of life. It was observed that chronic ankle instability subjects had reduced regional and global quality of life than their age-matched healthy counterparts and copers [32].

A recently published retrospective case-control study evaluated health-related quality of life using SF-36 in nineteen inversion ankle sprain patients and age-gendermatched controls. It reported a significant difference in only the general health subscale of SF-36 between the two groups [6].

A cross-sectional study was conducted in 34 subjects with functional ankle instability and 34 healthy controls. In this study, SF-36 and the Foot and Ankle Ability Measure (FAAM) and the FAAM-Sport version (FAAMS) were used to measure the quality of life and functional limitation respectively. It demonstrated lower scores on the SF-36 physical component summary scale, physical function domain scale, and bodily pain domain scale in participants with chronic ankle instability as compared to controls. Also, there was a positive association seen between the quality of life and functional limitation. This suggested that ankle impairment reduces the quality of life in subjects with functional ankle instability [33].

Another study evaluated differences in kinesiophobia, disability, and health-related quality of life between individuals with and without chronic ankle instability. It reported reduced function using the Foot and Ankle Ability Measure and quality of life on the Disablement

Table 3 Short Form-36 component summary and domain scores

\begin{tabular}{llll}
\hline Short Form-36 & Mean \pm SD & \multicolumn{2}{l}{$\mathbf{9 5 \% \text { confidence interval }}$} \\
\cline { 2 - 4 } & & Lower bound & Upper bound \\
\hline Physical component summary & $75.58 \pm 17.03$ & 69.23 & 81.93 \\
Physical functioning & $84.67 \pm 12.7$ & 79.91 & 89.42 \\
Role limitations due to physical health & $72.92 \pm 36.27$ & 59.37 & 86.46 \\
Bodily pain & $74.5 \pm 17.92$ & 67.81 & 81.19 \\
General health & $70.17 \pm 18.87$ & 63.12 & 77.21 \\
Mental component summary & $73.9 \pm 15.9$ & 67.94 & 79.87 \\
Vitality & $63.67 \pm 11.29$ & 59.45 & 87.73 \\
Social functioning & $81.25 \pm 14.21$ & 75.94 & 86.56 \\
Role limitations due to emotional problems & $73.34 \pm 38.56$ & 58.94 & 87.73 \\
Mental health & $77.33 \pm 13.59$ & 72.26 & 82.41 \\
\hline
\end{tabular}


Table 4 Correlations of Tampa Scale of Kinesiophobia with Foot and Ankle Ability Measure-Activities of Daily Living, Foot and Ankle Ability Measure-Sport scores, and Short Form-36 summary scores

\begin{tabular}{|c|c|c|c|c|c|c|c|c|}
\hline \multirow[t]{2}{*}{ Variable } & \multicolumn{2}{|c|}{$\begin{array}{l}\text { Foot and Ankle Ability Measure- } \\
\text { Activities of Daily Living }\end{array}$} & \multicolumn{2}{|c|}{$\begin{array}{l}\text { Foot and Ankle Ability } \\
\text { Measure-Sport }\end{array}$} & \multicolumn{2}{|c|}{$\begin{array}{l}\text { Short Form-36 } \\
\text { Physical component } \\
\text { summary }\end{array}$} & \multicolumn{2}{|c|}{$\begin{array}{l}\text { Short Form-36 } \\
\text { Mental component } \\
\text { summary }\end{array}$} \\
\hline & $r$ & $\mathrm{p}$ value & $r$ & $\mathrm{p}$ value & $r$ & $p$ value & $r$ & $p$ value \\
\hline Tampa Scale of Kinesiophobia & -0.22 & 0.25 & -0.5 & $0.005^{*}$ & -0.42 & $0.02^{*}$ & -0.28 & 0.14 \\
\hline
\end{tabular}

${ }^{*} p$ value less than 0.05 is statistically significant

in the Physically Active Scale, whereas increased fear of movement using the Tampa Scale of Kinesiophobia-11 and Fear-Avoidance Beliefs Questionnaire in chronic ankle instability subjects as compared to the control group [34]. Also, literature reports that chronic ankle instability disposes long-term restraints and debilitating effects during performance of recreational and occupational activities [35, 36]. This indicates that assessment of kinesiophobia, physical function, and health-related quality of life is imperative to provide deeper knowledge of the consequences linked with functional ankle instability.

There are some limitations of this study. The small sample size of the study limits the power of the study and the ability of the results to generalize the findings to a larger population. Also, there was no healthy control group incorporated to compare the level of kinesiophobia between functional ankle instability participants and healthy subjects. As a cross-sectional study design was incorporated, we were able to draw conclusions at a single time point only. Also, recall bias may be observed with respect to the FAAM questionnaire as it requires response from participants based on the past 1 week. We recommend future researchers should conduct longitudinal studies with a larger sample size to determine the relationship between these variables over time. Also, studies should be conducted to evaluate prevention strategies and interventions to target kinesiophobia and health-related quality of life in functional ankle instability individuals.

\section{Conclusion}

Increased fear of movement, reduced physical function, and health-related quality of life were observed in functional ankle instability individuals. Evaluation of patient's perception of function and psychological aspects is crucial to improve the quality of patient care. These components should be included during assessment which will provide a holistic and multimodal approach towards the understanding, planning, and rehabilitation of these patients.

\section{Abbreviations}

IdFAl: Identification of Functional Ankle Instability; FAAM: Foot and Ankle Ability Measure; TSK: Tampa Scale of Kinesiophobia; SF-36: 36-Item Short Form Health Survey questionnaire; FAAM-ADL: FAAM-Activities of Daily
Living; FAAM-S: FAAM-Sport; PCS: Physical component summary; MCS: Mental component summary

\section{Acknowledgements}

The authors acknowledge the patients for their participation in the study.

\section{Authors' contributions}

PW has contributed to the concept, design, literature search, data collection and analysis, manuscript preparation, editing, and review. VP has contributed to the concept, design, literature search, manuscript preparation, editing, and review. KV has contributed to the design, literature search, data collection and analysis, and manuscript preparation. The authors have read and approved the final manuscript.

\section{Funding}

The authors confirm that there is no financial support.

Availability of data and materials

The data sets generated and/or analyzed during the current study are available from the corresponding author on reasonable request.

\section{Declarations}

Ethics approval and consent to participate

The Institutional Research Review Committee, Mahatma Gandhi Mission's, College of Physiotherapy, Navi Mumbai (Reference no: MGM/COP/IRRC/133/ 2019), approved the study. Written informed consent was obtained from each participant in the language understood by them before commencing the study

\section{Consent for publication}

N/A

\section{Competing interests}

The authors declare that they have no competing interests.

\section{Author details}

${ }^{1}$ Department of Musculoskeletal Sciences, MGM College of Physiotherapy, Navi Mumbai, India. ${ }^{2}$ MGM College of Physiotherapy, Navi Mumbai, India.

Received: 26 December 2020 Accepted: 26 May 2021

Published online: 28 July 2021

References

1. Gribble PA, Bleakley CM, Caulfield BM, Docherty CL, Fourchet F, Tik-Pui-Fong D, et al. Evidence review for the 2016 International Ankle Consortium consensus statement on the prevalence, impact and long-term consequences of lateral ankle sprains. Br J Sports Med. 2016;50(24):1496505. https://doi.org/10.1136/bjsports-2016-096189.

2. Hootman JM, Dick R, Agel J. Epidemiology of collegiate injuries for 15 sports: summary and recommendations for injury prevention initiatives. J Athl Train. 2007:42(2):311-9.

3. Root HJ, Frank BS, Denegar CR, Casa DJ, Gregorio DI, Mazerolle SM, et al. Application of a preventive training program implementation framework to youth soccer and basketball organizations. J Athl Train. 2019;54(2):182-91. https://doi.org/10.4085/1062-6050-375-17.

4. O'Connor SR, Bleakley CM, Tully MA, McDonough SM. Predicting functional recovery after acute ankle sprain. PLoS One. 2013;8:e721-4. 
5. Agel J, Palmieri-Smith RM, Dick R, Wojtys EM, Marshall SW. Descriptive epidemiology of collegiate women's volleyball injuries: National Collegiate Athletic Association Injury Surveillance System, 1988-1989 through 20032004. J Athl Train. 2007:42(2):295-302.

6. Anandacoomarasamy A, Barnsley L. Long term outcomes of inversion ankle injuries. Br J Sports Med. 2005;39(3):e14.

7. Konradsen $L$, Bech L, Ehrenbjerg M, Nickelsen T. Seven years follow-up after ankle inversion trauma. Scand J Med Sci Sports. 2002;12(3):129-35. https:// doi.org/10.1034/j.1600-0838.2002.02104.x.

8. Hertel J. Functional anatomy, pathomechanics, and pathophysiology of lateral ankle instability. J Athl Train. 2002;37(4):364-75.

9. Panhale V, Walankar P, Chheda D. Chronic ankle instability - a review. Int J Sci Healthcare Res. 2020;5(4):394-8.

10. Delahunt E, Coughlan GF, Caulfield B, Nightingale EJ, Lin CW, Hiller CE. Inclusion criteria when investigating insufficiencies in chronic ankle instability. Med Sci Sports Exerc. 2010;42(11):2106-21

11. Hubbard TJ, Hertel J. Mechanical contributions to chronic lateral ankle instability. Sports Med. 2006;36(3):263-77. https://doi.org/10.2165/000072 56-200636030-00006

12. Santos MJ, Liu W. Possible factors related to functional ankle instability. J Orthop Sports Phys Ther. 2008;38(3):150-7. https://doi.org/10.2519/jospt.2 008.2524 .

13. Munn J, Sullivan SJ, Schneiders AG. Evidence of sensorimotor deficits in functional ankle instability: a systematic review with meta-analysis. J Sci Med Sport. 2010;13(1):2-12. https://doi.org/10.1016/j.jsams.2009.03.004.

14. Parker J, Nester CJ, Long AF, Barrie J. The problem with measuring patient perceptions of outcome with existing outcome measures in foot and ankle surgery. Foot Ankle Int. 2003;24(1):56-60. https://doi.org/10.1177/10711 0070302400109 .

15. Guyatt GH, Ferrans CE, Halyard MY, Revicki DA, Symonds TL, Varricchio CG, et al. Exploration of the value of health-related quality-of-life information from clinical research and into clinical practice. Mayo Clin Proc. 2007;82(10): 1229-39. https://doi.org/10.4065/82.10.1229.

16. Parsons JT, Snyder AR. Health-related quality of life as a primary clinical outcome in sport rehabilitation. J Sport Rehabil. 2011;20(1):17-36. https:// doi.org/10.1123/jsr.20.1.17.

17. Cella DF, Tusky DS. Measuring quality of life today: methodological aspects. Oncology. 1990;5:29-38.

18. Snyder AR, Parsons JT, Valovich McLeod TC, Curtis Bay R, Michener LA, Sauers EL. Using disablement models and clinical outcomes assessment to enable evidence-based athletic training practice, part I: disablement models. J Athl Train. 2008;43(4):428-36. https://doi.org/10.4085/1062-6050-43.4.428.

19. Vlaeyen EW, Linton SJ. Fear-avoidance and its consequences in chronic musculoskeletal pain: a state of the art. Pain. 2000;85(3):317-32. https://doi. org/10.1016/S0304-3959(99)00242-0.

20. Kori SH, Miller RP, Todd DD. Kinesiophobia: a new view of chronic pain behavior. Pain Manage. 1990;3:35-43.

21. Lundberg M, Grimby-Ekman A, Verbunt J, Simmonds MJ. Pain-related fear: a critical review of the related measures. Pain Res Treat. 2011.

22. Wikstrom EA. Fear of re-injury does not differ between those with and without chronic ankle instability. J Sports Sci Med. 2011;10(4):771-2.

23. Simon J, Donahue M, Docherty C. Development of the Identification of Functional Ankle Instability (IdFAl). Foot Ankle Int. 2012;33(9):755-63. https:// doi.org/10.3113/FAl.2012.0755.

24. Miller RP, Kori S, Todd D. The Tampa Scale: a measure of kinesiophobia. Clin J Pain. 1991;7(1):51-2.

25. Swinkels-Meewisse EJ, Swinkels RA, Verbeek AL, Vlaeyen JW, Oostendorp RA. Psychometric properties of the Tampa Scale for kinesiophobia and the fearavoidance beliefs questionnaire in acute low back pain. Man Ther. 2003;8(1): 29-36. https://doi.org/10.1054/math.2002.0484.

26. Martin RL, Irrgang JJ, Burdett RG, Conti SF, Van Swearingen JM. Evidence of validity for the Foot and Ankle Ability Measure (FAAM). Foot Ankle Int. 2005; 26(11):968-83 Microsoft Word - AbilityMeasure.doc (aaos.org).

27. Matheny LM, Clanton TO. Rasch analysis of reliability and validity of scores from the Foot and Ankle Ability Measure (FAAM). Foot Ankle Int. 2020;41(2): 229-36. https://doi.org/10.1177/1071100719884554 Epub 2019 Oct 30. PMID: 31665926.

28. Ware JE, Kosinski M, Dewey JE. SF-36 health survey: manual and interpretation guide: quality metric Inc. 2000. Gandek B. 36-Item Short Form Survey Instrument (SF-36) | RAND

29. Ware J. SF-36. Health survey update. Spine. 2000;25(24):3130-9.
30. Lentz TA, Sutton Z, Greenberg S, Bishop MD. Pain related fear contributes to self-reported disability in patients with foot and ankle pathology. Arch Phys Med Rehabil. 2010;91(4):557-61. https://doi.org/10.1016/j.apmr.2009.12.010.

31. Whogol Group. The World Health Organization quality of life assessment (WHOQOL): position paper from the World Health Organization. Soc Sci Med. 1995;41(10):1403-9.

32. Kosik KB, Johnson NF, Terada M, Thomas-Fenwick AC, Mattacola CG, Gribble PA. Health-related quality of life among middle-aged adults with chronic ankle instability, copers, and uninjured controls. J Athl Train. 2020;55(7):7338. https://doi.org/10.4085/1062-6050-190-19.

33. Arnold BL, Wright CJ, Ross SE. Functional ankle instability and health-related quality of life. J Athl Train. 2011;46(6):634-41. https://doi.org/10.4085/10626050-46.6.634.

34. Houston MN, Van Lunen BL, Hoch MC. Health-related quality of life in individuals with chronic ankle instability. J Athl Train. 2014;49(6):758-63. https://doi.org/10.4085/1062-6050-49.3.54.

35. Houston MN, Hoch JM, Gabriner ML, Kirby JL, Hoch MC. Clinical and laboratory measures associated with health-related quality of life in individuals with chronic ankle instability. Phys Ther Sport. 2015;16(2):169-75. https://doi.org/10.1016/j.ptsp.2014.10.006.

36. Hiller CE, Nightingale EJ, Raymond J, Kilbreath SL, Burns J, Black DA, et al. Prevalence and impact of chronic musculoskeletal ankle disorders in the community. Arch Phys Med Rehabil. 2012;93(10):1801-7. https://doi.org/10.1 016/j.apmr.2012.04.023.

\section{Publisher's Note}

Springer Nature remains neutral with regard to jurisdictional claims in published maps and institutional affiliations.

\section{Submit your manuscript to a SpringerOpen ${ }^{\circ}$ journal and benefit from:}

- Convenient online submission

- Rigorous peer review

- Open access: articles freely available online

- High visibility within the field

- Retaining the copyright to your article

Submit your next manuscript at $>$ springeropen.com 